TEI

OURNAL OF THE Journal of the Text Encoding Initiative

Issue 12 | July 2019 - May 2020

Selected Papers from the 2017 TEI Conference

\title{
Inside Digital Dinah Craik: Feminist Pedagogy, Cognitive Apprenticeship, and the TEI
}

Kailey Fukushima and Karen Bourrier

\section{OpenEdition}

Journals

Electronic version

URL: http://journals.openedition.org/jtei/2185

DOI: 10.4000/jtei.2185

ISSN: 2162-5603

Publisher

TEl Consortium

\section{Electronic reference}

Kailey Fukushima and Karen Bourrier, « Inside Digital Dinah Craik: Feminist Pedagogy, Cognitive Apprenticeship, and the TEl », Journal of the Text Encoding Initiative [Online], Issue 12 | July 2019 - May 2020, Online since 14 August 2019, connection on 26 June 2020. URL : http:// journals.openedition.org/jtei/2185; DOI : https://doi.org/10.4000/jtei.2185

For this publication a Creative Commons Attribution 4.0 International license has been granted by the author(s) who retain full copyright. 


\title{
Inside Digital Dinah Craik: Feminist Pedagogy, Cognitive Apprenticeship, and the TEI
}

\author{
Kailey Fukushima and Karen Bourrier
}

\section{ABSTRACT}

In this essay, we describe our collaborative work as students and teachers on a TEI edition of Dinah Mulock Craik's correspondence. Inside Digital Dinah Craik, our pedagogy is collaborative and inclusive, attentive to the material conditions of both the text and our labor, and is reproducible. We follow a cognitive apprenticeship model of education that emphasizes a community of practice where learners become increasingly proficient until, ideally, they are no longer apprentices but genuine collaborators. In this paper, we demonstrate how the five stages of apprenticeship learning-modeling, approximating, fading, self-directed learning, and generalizing (Hansman 2001, 47)-help us to foster what scholars such as Anne Balsamo, Elizabeth Losh, Jacqueline 
Wernimont, Laura Wexler, and Hong-An Wu call the "foundational ethical principles" (Balsamo 2011, 162-3) and "feminist virtues" (Losh et al. para. 26) of collaboration-confidence, humility, flexibility, integrity, and intellectual generosity.

\section{INDEX}

Keywords: correspondence, feminism, pedagogy, digital humanities, student teaching, cognitive apprenticeship

\section{ACKNOWLEDGEMENTS}

We would like to acknowledge and thank the past and present members of the Digital Dinah Craik project: Hannah Anderson, Keila Aleman, Alyson Bennett, Will Best, Sidney Cunningham, Jaclyn Carter, Aaron Ellsworth, Kerry-Leigh Fox, Kylee-Anne Hingston, Christie Hurrell, Sonia Jarmula, Kelsey Jacobi, Sarah Kent, Elizabeth Ludlow, Janice Parker, Zainub Rahman, Ingrid Reiche, Pippa Ruddy, Lecia Givogue Stevenson, and Lindsey Stewart. At the University of Calgary, we would like to thank John Brosz and Paul Pival in Libraries and Cultural Resources for their assistance with data visualization and querying our data set. Finally, we would like to thank the audience at the 2017 TEI-C Conference and Members' Meeting in Victoria, BC, and the anonymous referees of the jTEI for their helpful suggestions for this paper.

\section{Introduction}

1 Women writers hoping to succeed in Victorian England had a long apprenticeship to undertake. The informal elements of their apprenticeship often included writing extensively for periodicals, networking at those literary salons which welcomed women, and sometimes even moving to London to be closer to opportunities in the literary world (Shattock 2015, 29-31). The popular Victorian writer Dinah Craik pursued all these avenues in her literary apprenticeship. Her career path was similar to the way in which a contemporary graduate student might seek opportunities to publish first on professional blogs then in journals, to network and collaborate at conferences and on digital humanities projects, and to move to another city to pursue an advanced degree. In the apprenticeship model of education-which pays attention to the ways in which doing real, hands- 
on work can help transform students into professionals-we find an apt theoretical explanation for both the careers of successful Victorian writers like Craik, and for our own work on a TEI edition of her correspondence.

2 In this essay, we describe our work as students and teachers on a TEI edition of Dinah Mulock Craik's correspondence. We argue that an apprenticeship model of education helps us to build a collaborative and inclusive model of pedagogy, one which is attentive to the material conditions of both the text and our labor, and is reproducible. According to Catherine Hansman, who writes about teaching adult literacy, "paying attention to the interaction and intersection among people, tools, and context within a learning situation" is essential to learning in context $(2001,44)$. We find that this cognitive apprenticeship model helps us to involve students in a complex TEI research project while fostering what scholars such as Anne Balsamo, Elizabeth Losh, Jacqueline Wernimont, Laura Wexler, and Hong-An Wu call the "foundational ethical principles" (Balsamo 2011, 162-3) and "feminist virtues" (Losh et al. para. 26) of collaboration-confidence, humility, flexibility, integrity, and intellectual generosity. In this paper, we demonstrate how the five stages of apprenticeship learning-modeling, approximating, fading, self-directed learning, and generalizing (Hansman 2001, 47)-help us to turn research assistants into collaborators.

We approach the apprenticeship model of education through a feminist pedagogical lens. Following earlier work in feminist pedagogy, we hope to demonstrate how an apprenticeship model of education can join the ranks of feminist teaching practices that aim to de-center the patriarchal and hierarchical models of authority that prevail in traditional classrooms. ${ }^{1}$ Feminist pedagogy is a branch of critical pedagogy, and owes much to Brazilian educator Paolo Freire's argument against hierarchical teaching practices. In Pedagogy of the Oppressed, Freire writes that many learning environments follow a "'banking' concept of education" (2018,72). Within this model, "individuals cannot be truly human" because teachers treat learners as receptacles for knowledge rather than as active participants in intellectual processes (Freire 2018, 72). Feminist pedagogy rejects this hierarchical model of education and "situate[s] learning as a collaborative rather than top-down process" (De Santis and Serafini 2015, 64). A feminist pedagogical model recognizes humanity and difference within the classroom, and attends to the fact that learners have diverse individual and social experiences that are historically situated, embodied, affective, and material (Losh et al. 
2016, para 4). Although the apprenticeship model of education begins from a traditional binary of teacher and learner and is not explicitly feminist, it aims to empower learners at each step of their education, and thus it gradually works toward building a non-hierarchical community of practice.

\section{Dinah Craik and Literary Apprenticeship}

4 The apprenticeship model of pedagogy mirrors Dinah Craik's experience as a woman writer in nineteenth-century London. In the 1840s, she served what we might term "a literary apprenticeship" writing stories for literary magazines. As Sally Mitchell writes, Craik "forged ahead ... through the streets and into the editors' offices, placing a poem here, a story there, an article elsewhere, making her contracts, learning her craft and grinding out the words" (1983, 9). At the height of her apprenticeship, she wrote "five-thousand-word stories every two or three weeks," placing them in weekly magazines or monthly journals (Mitchell 1983, 9). Craik began to learn her craft in the social and material context of periodical publishing, working with feedback from magazine editors and other writers to improve before taking on a three-volume novel. Her success culminated with the publication of her fifth novel, John Halifax, Gentleman, a rags-to-riches tale that tells the story of an orphan who becomes a Captain of Industry with nothing but his head and his own two hands. John Halifax, Gentleman was popular on both sides of the Atlantic, and was widely read until around World War II. Craik's own story was very different; far from learning on her own, she continued to be deeply indebted to the social and material contexts of nineteenthcentury publishing as she learned her own craft as a writer.

Despite her tremendous popularity, today we know very little about Dinah Craik beyond her published work. Our project, Digital Dinah Craik, seeks to digitize her unpublished manuscript correspondence using methods developed by the TEI community. Over one thousand letters and fourteen years of Craik's diaries exist in archives across the U.S. and the U.K.: most importantly the Mulock Family Papers at UCLA, the Craik collection in the Harry Ransom Center at the University of Texas at Austin, and the Parrish Collection of Victorian novelists at Princeton University. The letters include unpublished correspondence to Victorian luminaries including Elizabeth Barrett Browning and Oscar Wilde, as well as personal correspondence to her brother in the Crimea and her father in the Staffordshire Insane Asylum. These letters are important not only because they shed light on the career of an important and well-connected author as well as on the Victorian 
era in general, but because of what they can tell us about the venues, types of publications, and networks of connection that could sustain a nineteenth-century woman writer's career for upwards of forty years.

6 Our work in creating a digital edition of Craik's letters joins the efforts of feminist scholars to make difficult-to-access manuscript correspondence of nineteenth-century women writers widely available. While codex projects like the Pilgrim edition of The Letters of Charles Dickens, which comprises twelve volumes and was edited over almost fifty years (from 1965 to 2002), or Gordon S. Haight's monumental nine-volume edition of The George Eliot Letters (edited from 1954 to 1978), have made the letters of canonical Victorian authors widely available, one of the challenges of working on popular nineteenth-century writers has been the lack of access to their correspondence. For the most part, the letters of popular women writers remain in manuscript only, and have often not even been quoted in scholarship, leaving us with a lack of contextual information about the lives and careers of these popular writers. Letters such as Dinah Craik's have much to tell us about the working conditions of popular women writers, from how they negotiated their book contracts to how much they were paid for work in periodicals or volume form. Moreover, they can help us to shine light on the affective communities and networks of support that empowered women writers such as Dinah Craik to maneuver in the gendered landscape of the Victorian publishing industry.

7 Many of the influential projects in Victorian studies in the digital humanities have focused on canonical male authors, including the William Blake Archive and Jerome McGann's The Rossetti Archive. As Marjorie Stone and Keith Lawson point out, many of the "large scale single-author digital projects on nineteenth-century literature" that scholars have identified as exemplary "feature traditionally canonical white male writers"; one of the problems that scholars working on non-canonical writers face is that they must often accomplish the "foundational tasks of reinterpreting and editing," which may leave little time "to seize the opportunities that digital technologies provide" $(2012,112-113)$. As Beshero-Bondar and Raisanen point out, in contrast to digital humanities projects focusing on male writers, "a 'more is more' approach has structured the major, lasting digital projects that address women writers. This collective comprehensiveness in the scale of such projects would seem pointedly to counteract a more mainstream 'digital turn' in archival development, which has been accumulating a data-rich stock of the dominant 
western literary canon, individual writer by individual writer" $(2017,740)$. Beshero-Bondar's project, Digital Mitford, demonstrates how the intensive study of a single non-canonical author can reveal "social networks [that] highlight the people and contexts important to establishing a strong reputation in periodical publishing and theatrical production" (Beshero-Bondar and Raisanen $2017,746)$. Indeed, this situation is changing as scholars are editing and digitizing women writers simultaneously, demonstrating in the process the way that digital tools like the TEI can help us to carve out a space to reinterpret these authors and their works.

8 Ten years after the completion of The Rossetti Archive in 2008, an increasing number of digital humanities scholars are allocating their time and labor towards making the writing of women writers accessible. ${ }^{2}$ Charlotte Mitchell, Ellen Jordan and Helen Schinske have worked to make the complete correspondence of Craik's contemporary, the novelist Charlotte Yonge, available for the first time, with the hope that the digital edition will provide a "substantial foundation of facts for the study of her fiction, her historical and educational writing and her journalism, and help to illuminate her biography and also her significance in the cultural and religious history of the Victorian age" (Mitchell, Jordan, and Schinske, n.d.). ${ }^{3}$ Liz Stanley's XML edition of The Olive Schreiner Letters Online aims to make over five thousand of the late Victorian novelist's letters available. ${ }^{4}$ Most influentially for our project, Elisa Beshero-Bondar's aforementioned Digital Mitford Project uses TEI standards to digitize the correspondence of Mary Russell Mitford, aiming to "freely and fully publish" over two thousand letters "previously available only in manuscript form in obscure archives or in bowdlerized published forms" (Beshero-Bondar 2018).

9 In addition to following the TEI Guidelines for encoding correspondence, we concentrate our efforts on tagging the people, places, organizations, and publications mentioned in Craik's letters. Ultimately, we hope that this careful contextual encoding will help us uncover the epistolary networks that could bolster a woman writer's career; however, the first step in our project is to undertake the labor-intensive process of transcribing and encoding the letters themselves. In the next section, we outline the origins of our project, paying particular attention to the material and economic conditions that underpin our work. 


\section{Project Background} Winter 2015 grad seminar on "Digitizing Women Writers," where ten graduate students transcribed and encoded thirty letters, and worked together to develop our first encoding guidelines. Because of the amount of training involved, it became advisable to involve research assistants who would be able to work on the project for longer than a semester. We found ourselves faced with what Susan Brown et al. describe as the "fairly basic choice" in digital humanities projects between "greater complexity and a fairly tight-knit group of collaborators, and lesser complexity and a more open collaborative model" $(2006,324)$ and considered that our project fell within the former camp. Because of the relative complexity of the project, we tend to draw research assistants from Bourrier's upper-level undergraduate Victorian literature courses. Thus, to begin with, team members on the project are already in their third or fourth year of an English degree, and have some background in Victorian literature, which they can bring to a project that combines nineteenth-century history, paleography, and the TEI. ${ }^{5}$ students over a longer period of time rather than over a single semester has been enabled by the funding our project received. Two main streams of funding made our work possible: internal grants from the University of Calgary, and an external grant from SSHRC (the Social Science and Research Council of Canada). In terms of internal funding, two of our research assistants, Kailey Fukushima and Hannah Anderson, won University of Calgary research awards that allow undergraduates to work full-time with a professor over the summer. These PURE awards (Program for Undergraduate Research) pay students between $C \$ 3000$ and $C \$ 6000$ depending on the number of weeks they work full-time on a project. The PURE awards have been helpful in supplementing the funding pool available for our project. But they also allow our undergraduate researchers to practice writing grant proposals, and enable them to bring their own funding and research interests to Digital Dinah Craik. This, in turn, helps to decenter the economic power dynamics of our working group - providing an alternative to a traditional research project model, where all funding would flow through the principal investigator. 
12 We were also fortunate to procure a SSHRC Insight Development Grant, which enabled us to hire research assistants during the semester. Over the summer of 2017 , we transitioned from a classroom model, where graduate students received credit for participating in the project, to a labbased model, where undergraduate and graduate research assistants are paid to work on Digital Dinah Craik in a collaborative environment for three hours a week. In our digital humanities lab, which took place in a room equipped with large screens and Wi-Fi in our campus library, the Taylor Family Digital Library, new research assistants interact with more experienced project members using the tools of the trade-computers equipped with an oXygen licence-in order to learn the basics of paleography, TEI, and prosopography.

13 Although we may have been able to take on a smaller TEI project, as Bourrier did in her classroom, without this level of funding, securing internal and external funding for Digital Dinah Craik has helped us to make great strides in our project. Funding has allowed us to hire students full-time on the project, and to buy oXygen licenses for all research assistants on the project. ${ }^{6}$ We currently have over three hundred letters published on TAPAS, with another one hundred and eighteen that are close to completion. In the remainder of this paper, we will outline how the apprenticeship model of education has helped us to reach this stage in our collaborative work.

\section{Apprenticeship Learning and the TEI}

\subsection{Modeling}

14 The first stage in the cognitive apprenticeship model of education is modeling, which Hansman writes takes place in two ways: (1) "Behavioural modeling," where learners watch "experienced members of a community" perform an action, and (2) "Cognitive Modeling," where experienced practitioners explain how the activity is done $(2001,47){ }^{7}$ We find TEI templates and a lab-based model where immediate feedback and coaching is available to be essential for success in the modeling stage.

We also argue that modeling has been essential to the success of the TEI community in general, as our project has benefited from the modeling of other projects. Before beginning work on Digital Dinah Craik, Bourrier served in what we might term "a cognitive apprenticeship" on The Digital Mitford Project. Elisa Beshero-Bondar, that project's PI, has generously made their models-a 
codebook and TEI template-open-access. We took the template for Mitford's letters as our starting point, and we now train students using a similar template that we have developed for Digital Dinah Craik. We begin with cognitive modeling and textual encoding on a macro-level. In the first session, our goal is to get students to bring the knowledge they already have about what letters are and how they work into conversation with the idea of markup. Research assistants begin their training with a brief overview of what the TEI is, its vocabulary, and why we use it. Next, we ask students to brainstorm what the formal elements of a letter are: visually, how do you know that a document is a letter rather than a sonnet or a play? Research assistants quickly respond that letters typically have an address, a date, and a signature, among other formal features. We next show students how we would tag the formal features that they have identified. We open our TEI letter template and explain the macro-level structure of a TEI letter in order to familiarize research assistants with the functions of the <teiHeader $>,<$ respstmt $>$, and the <opener $>$, body paragraphs, $<$ closer $>$, and <postscript>. We would emphasize that this presentation is short, about ten minutes, and quickly moves to behavioral modeling as we demonstrate how we would encode an actual letter. As a group, we walk new project members through the template using text from a previously transcribed letter. We ask them, based on their knowledge of how letters work, where they think lines such as "My dear friend," and "Lynover Cottage, Kilburn. London" would go in our template, and they are quick to suggest <opener $>$ and <datel ine $>$ as the correct containers for these lines. We explain our process and reasoning to the group along the way, combining behavioral and cognitive modeling.

17 As we model our TEI practice, we move inward from larger structures of correspondence to the smaller structures. After we have worked our way through macro-level encoding, our next step is to explain contextual encoding. We introduce our use of contextual tags such as <persName>, <placeName>, <title>, and <orgName>, and explain how we use aref attributes to link tags to specific axml:ids in our TEI prosopography. After this presentation, the group returns to the encoded letter and we ask new research assistants whether they see any people or places mentioned in the body of the letter. Once again, students are able to pick out names such as "Elizabeth Barrett Browning" and places like "Italy" quite quickly; we move from straightforward examples to potentially trickier ones. Picking out Elizabeth Barrett Browning's Aurora Leigh as the title of a book, for example, requires either some previous knowledge about Victorian literature 
or reading contextual clues in the letter, as when Craik refers to it as "the completest Poem, if not one of the grandest books, that any woman ever wrote" (Craik 1856). As a group, we work our way through a single letter, tagging all mentions of people, places, book titles, and organizations and point them towards their respective entries in the prosopography. All in all, the process of modeling our encoding process takes about thirty to forty-five minutes, and we try to ask as many questions as possible to involve students in the learning, and to have them apply the everyday knowledge that they already have about letters and letter-writing to the new arena of encoding.

\subsection{Approximating}

Research assistants move from modeling to encoding their own letter within the first lab-session, and thereby enter the approximating stage of the apprenticeship model of education. In this stage, learners "try out the activity while articulating their thoughts about what they plan to do and why" and then reflect on the process (Hansman 2001, 47). After more experienced project members model encoding, all project members are assigned a subset of previously transcribed letters to work with on their own. At this point, we hand out hard copies of our Digital Dinah Craik codebooka live catalog of our project standards and tagset-so that research assistants have a physical guide to follow along with. ${ }^{8}$ We find that giving new research assistants print copies of our otherwise digital codebook helps to eliminate toggling between oXygen and the codebook, and allows them to focus on the task of encoding. When working with undergraduate research assistants, we begin with short letters that Bourrier has already transcribed in her time in the archives to focus on the encoding alone. We start and end each lab session by talking about how our work is going and what types of encoding errors are coming up. This type of discussion and reflection is key to students' learning. In fact, perhaps the largest unanticipated problem with our learning model is overcoming students' shyness. The three new research assistants Bourrier hired for the Winter 2017 semester were all quiet students who preferred to work on their own, to the extent that they would try to figure out an encoding error on their own for twenty minutes rather than asking for help. We tried to address this issue by modeling discussion and by checking in periodically. In the future, we plan to break up the initial encoding checks and require new research assistants to share their work in three stagesstructure, context, and then prosopography. 


\subsection{Fading} some of the scaffolding as they begin to work independently. This is what Hansman identifies as the fading process, as "scaffolding and other support gradually decrease as learners' abilities increase" (47). After undergraduate research assistants encode approximately ten transcribed letters over the course of around half a dozen three-hour lab meetings, we challenge them to work on the transcription and encoding of a longer and more complex letter. This task takes place within the supportive environment of the lab, where research assistants can continue to ask questions about difficult words, research strategies for people mentioned in the letters that did not show up in the Oxford Dictionary of National Biography, and TEI errors. Some research assistants go on to do this work independently in a full-time capacity. For many research assistants, fading is the most difficult phase of the apprenticeship. Research assistants typically have no experience in the TEI or in reading nineteenth-century handwriting, and yet they are tasked with producing near-perfect encoded transcriptions of handwritten letters in order to prepare them for scholarly publication. The initial results can be messy, but we have learned to embrace mess as a key learning and teaching opportunity, and to accept it as a key aspect of our praxis. For, as Elizabeth Losh, Jacqueline Wernimont, Laura Wexler, and Hong-An Wu remind us, embracing "messiness" is a feminist act that helps us to counteract "popular notions of digital media as neat, clean, and hyper-rational" instead of subjective, situated, and material (2016, para 8). The fading phase also requires research assistants to develop a deep familiarity with our TEI prosopography-they learn how to navigate an expansive TEI file using some basic XPath as well as how to conduct and encode research according to our project standards. Initially, each RA uses oXygen on their own computer. Simultaneously, we use whiteboards to compile a list of prosopography entries that are being developed in real time. Because we tend to all work on one archival collection at a time, the same people often turn up in multiple research assistants' letters, and we must collate information from each letter as we work to prevent duplication. This model encourages new research assistants to query each other's transcriptions while also working together to contribute to the project. 
22 The fading phase, while difficult and often long, builds necessary research skills, encourages collaborative scholarship, and fosters confidence and independence. Part of the difficulty inherent in this phase of apprenticeship stems from the high demands of our TEI prosopography. We aim to encode all <person> entries with the same level of detail regardless of how well-known the person mentioned in the letter is. This means that our research assistants put significantly more time and labor into researching women, families, and the working classes-people whose lives are not necessarily detailed in traditional scholarly sources such as the Oxford Dictionary of National Biography. And this, in our view, is good.

\subsection{Self-Directed Learning}

It is often our project members' complex work in the TEI prosopography that shifts them to the next phase of apprenticeship, self-directed learning. Students working on the project have been highly successful (and creative) in pursuing contextual research combining nineteenth-century newspaper and genealogical databases. We would add that the TEI itself also affords multiple opportunities for self-directed learning. In lab sessions, we always emphasize that our encoding practices are flexible, and we encourage research assistants to query our encoding practices as they gain independence in the project. Any proposals for amendments, additions, or deletions are presented, discussed, and agreed upon via consensus in our group lab sessions.

Kailey Fukushima's work on Digital Dinah Craik exemplifies this phase of the apprenticeship model of education. Fukushima began working on the project as an advanced undergraduate, and she became deeply interested in the TEI, following current discussions on the TEI listserv and GitHub repository issue tickets, and thinking critically of alternative encoding practices. After a year and a half of working on the project, she prompted the team to make several changes to the original tags. At Fukushima's behest, we changed the values of the @sex attribute in our TEI prosopography from the numerical ISO standards to more descriptive value options-M, F, and $\mathrm{U}$ for unknown, with alternative options for confirmed intersex, non-binary, or transgender people. This amendment helped us to address the false hierarchy in the ISO standards where 1 is male and 2 is female; however, as Vanessa Hannesschläger and Peter Andorfer point out in "Having Sex in the TEI: The TEI 2016 Gender Check," this change does not reflect the fact that we are actually encoding the gender of historical people and not their biological sex. Fukushima also 
suggested that we add a < residence> tag with the datable attributes @ f rom and @to to our <person> entries. This allows us to track and document Craik's many home addresses and will help future research assistants to provide more accurate date range estimates for undated letters. Following the July 2017 release of the TEI 3.2.0 (Telstar) Guidelines, Fukushima suggested that we add the new @type attributes to <occupation> tags to distinguish the many nineteenth-century creative types who listed other "official" professions in census reports. In these cases, Fukushima identified a shortcoming in our available tags, turned to the TEI Guidelines and community for solutions, and then proposed changes at our weekly lab discussion. This kind of self-directed learning is encouraged of all research assistants-it helps them become more fluent in the affordances of TEI, fosters their integrity as collaborators, and works towards our group's ultimate aim of nonhierarchical intellectual generosity.

At this point in their apprenticeship, we encourage research assistants to consider applying for additional training opportunities. Bourrier budgets Digital Humanities Summer Institute (DHSI) funding for research assistants into grant applications so that our project members have the opportunity to expand their knowledge of TEI outside of the context of Digital Dinah Craik. We ask project members who attend workshops, seminars, or conferences to teach the team any relevant skills they learned upon their return. This kind of self-directed learning opportunity is positioned to benefit early-career scholars by providing them with hands-on learning and teaching experiences. It also encourages us to practice generosity and humility in our scholarship, and to recognize ourselves as a community of learners as well as a community of practice.

\subsection{Generalizing}

The final step in the apprenticeship model of education is generalizing. In this phase, students take on more leadership roles and are asked to start teaching their skills to new project members. Some of the students who work on Digital Dinah Craik will go on to develop their own projects in the digital humanities. And, if they stay on the project team, they are encouraged to query our dataset with their own research questions. But we hope that all the students who work on this project have gained greater competence and confidence with digital tools and the way that they relate to their English degrees. We have already seen two undergraduate research assistants use their experience on Digital Dinah Craik to gain full-time employment as digitization assistants in Libraries 
and Cultural Resources at the University of Calgary. While this role does not require experience in TEI specifically, former research assistants who have taken on this role report that working on a digital humanities project gave them the confidence needed to know they could learn new digital tools and techniques. Supervisors in Libraries and Cultural Resources similarly report that the attention to detail and critical thinking that students learn working on a TEI project like Digital Dinah Craik gives them the skills that they need to work as digitization assistants in the library.

\section{Reflection and Conclusions}

27 As we reflect on our pedagogy and praxis, we are aware that this project has limitations. Getting research assistants to the final two stages of the apprenticeship model of education, those of selfdirected learning and generalization, is difficult and does not happen in all cases. Geoffrey Rockwell and Stéfan Sinclair note that digital humanities projects working with an apprenticeship model raise the real issue of how to "gracefully correct and encourage quality" in student work. They write that apprenticeship "is a very different relationship than marking an assignment that has no real purpose beyond assessment" (2014, $198 \mathrm{n} 32)$. To put this in practical terms, Bourrier can confirm that it is much easier to give a student a $\mathrm{B}+$ on a paper that shows effort and promise than it is to send back multiple TEI letters that show effort and promise but must be perfect for publication.

28 A related challenge has been getting students to be critical of other project members' encoding and transcription, and of Bourrier's in particular. To address this issue, we have had discussions as a team about what it means to prepare a scholarly edition for digital publication. But research assistants are understandably apt to presume that the work of more experienced project members is correct. To foster a spirit of critical inquiry and collegiality, we plan to implement a rule that everyone must query at least three points of transcription or encoding in every letter, no matter whether the professor or the newest undergraduate on the project has done the work.

Despite these challenges, the fact that this project is ultimately meant for publication, and that we do publish finished letters on the TEI Archiving Publishing and Access Service (TAPAS) as we go, can also be tremendously encouraging for students and research assistants. Students in Bourrier's 
graduate class, as well as undergraduate research assistants, are able to add the letters they have transcribed and encoded as some of the first publication lines on their CVs, and many research assistants also gain valuable teaching experience as they mentor new students on a project. In sum, a feminist collaboration combined with the cognitive apprenticeship model has worked well for our project and has allowed us to decenter our power dynamics. Jacqueline Wernimont raises an important point when she notes that "in most digital scholarly projects, collaboration is happening between a small set of trained graduate students, faculty, and IT and library staff' (2013, para 19). She acknowledges that the material and economic conditions of labor in the academy have an impact on the size of the collaborative group, but questions whether we are "keeping non-professional users out of production to protect both academic privilege and the status of the traditional archive" and whether we should "be looking to feminist digital literary projects to push the possibilities of decentering even further" (2013, para 19). Our pedagogy and praxis in Digital Dinah Craik prepares undergraduate and graduate students to take on a real role in determining our encoding practices as well as the future of the project.

31 Finally, we find that we have started to create a community of practice that is relatively easy for others, such as students, librarians, and community members, to join. Over the course of our project, two librarians, Christie Hurrell, Digital Initiatives and Scholarly Communication Librarian, and Ingrid Reiche, Metadata Librarian, have joined our regular meetings to keep up their TEI skills while contributing to a live project, and they have had much to contribute to our knowledge base as well. We have also had a member of the Calgary community, Alyson Bennett, join our meetings to contribute her knowledge of genealogy and to research the people mentioned in the letters. While the advent of the internet and laptop computers have made it possible for students and faculty members alike to do more of their work remotely, we find that moving the research process back into the university, and into the library in particular, and having a physical meeting at the same time and in the same place on a weekly or monthly basis, makes the work that we are doing more visible to the community and helps us accomplish our research goals.

We think that the apprenticeship model is one that Dinah Craik would have approved of; in fact, it was a model that she seemed to follow in her own professional writing life. Craik benefited from the mentorship of more established women writers, such as Anna Maria Hall, early in her career, and she energetically mentored both men and women artists and writers once she was 
an established writer. Many of the letters we are digitizing give examples of concrete help she offered writers early on in their career in negotiating with editors and publishers. She wrote to the editor of a prestigious literary magazine, The Cornhill, offering a story by one of her young friends, and praising the publication for "its introduction of new young names instead of worn out old ones-which is always a success" (Craik 1883). One friend of Craik's remembered her as "the natural confidant, adviser, patron saint of girls, from the time when she was little older than her devotees" (Oliphant 1887, 84). Thus far, most of the team members working on our project have identified as women, and most have been initially intimidated by the technological aspects of the project. By the end of the apprenticeship process, however, most project members report that it is actually the handwriting and the research on nineteenth-century people and places that are the most difficult part of the project, not the technical aspects of the TEI. It is our hope that working step-by-step through the five stages of apprenticeship will help us build and maintain an inclusive feminist collaborative through which students can gain competence and confidence as digital humanities researchers.

\section{BIBLIOGRAPHY}

Balsamo, Anne. 2011. "Designing Learning: The University as a Site of Technocultural Innovation.” In Designing Culture: The Technological Imagination at Work, 133-183. Durham: Duke University Press. https:// doi.org/10.1215/9780822392149-005.

Beshero-Bondar, Elisa. 2018. "Methods and Practice." Digital Mitford: The Mary Russell Mitford Archive. Last modified February 27, 2018. http://digitalmitford.org/about.html.

Beshero-Bondar, Elisa, and Elizabeth Raisanen. 2017. "Recovering from Collective Memory Loss: the Digital Mitford's feminist project." Women's History Review 26 (5): 738-750. https:// doi.org/10.1080/09612025.2016.1166882.

Brandt, Barbara LeGrand, James. A. Farmer, Jr., and Annette Buckmaster. 1993. "Cognitive Apprenticeship Approach to Helping Adults Learn." New Directions for Adult and Continuing Education 59: 69-78. 
Brown, Susan, Patricia Clements, and Isobel Grundy. 2006. "Sorting things in: Feminist knowledge representation and changing modes of scholarly production." Women's Studies International Forum 29 (3): 317-325. https://doi.org/10.1016/j.wsif.2006.04.010.

Cohee, Gail E., Elisabeth Daumer, Theresa D. Kemp, Paula M. Krebs, Sue A. Lafky, and Sandra Runzo. 1998. The Feminist Teacher Anthology: Pedagogies and Classroom Strategies. New York: Teachers College Press.

Crabtree, Robbin D., David Alan Sapp, and Adela C. Licona, eds. 2009. Feminist Pedagogy: Looking Back to Move Forward. Baltimore: Johns Hopkins University Press.

Craik, Dinah Mulock. 1863. "Letter to Elizabeth Barrett Browning. December 18, 1856." Digital Dinah Craik on TAPAS. http://tapasproject.org/digitaldinahcraik/files/letter-dinah-mulock-craik-elizabethbarrett-browning-18-december-1856.

-_-. 1883. “Letter to James Payn, October 29, 1883.” Digital Dinah Craik on TAPAS. http://tapasproject.org/ digitaldinahcraik/files/letter-dinah-mulock-craik-james-payn-29-october-1883.

De Santis, Carm and Toni Serafini. 2015. “Classroom to Community: Reflections on Experiential Learning and Socially Just Citizenship." In Feminist Pedagogy in Higher Education: Critical Theory and Practice, edited by Tracy Penny Light, Jane Nicholas, and Renée Bondy, 59-75. Waterloo: Wilfrid Laurier University Press.

Freire, Paulo. 2018. Pedagogy of the Oppressed. 50th Anniversary ed. Translated by Myra Bergman Ramos. New York: Bloomsbury.

Haight, Gordon. 1954-1978. The George Eliot Letters, vol. 1-9. New Haven: Yale University Press.

Hannesschläger, Vanessa, and Peter Andorfer. 2017. "Having Sex in the TEI: The TEI 2016 Gender Check." Presentation at the TEI-C Conference, Victoria, BC, Nov. 11-15, 2017. https://hcmc.uvic.ca/tei2017/ abstracts/t_100_hannesschlager_andorfer_gender.html.

Hansman, Catherine. 2001. "Context-Based Adult Learning." New Directions for Adult and Continuing Education, 89: 43-52. doi:doi:10.1002/ace.7.

Losh, Elizabeth, Jacqueline Wernimont, Laura Wexler, and Hong-An Wu. 2016. “Putting the Human Back into the Digital Humanities: Feminism, Generosity, and Mess." In Debates in the Digital Humanities, edited by Matthew K. Gold and Lauren F. Klein. http://dhdebates.gc.cuny.edu/debates/text/61.

Maher, Frances A., and Mary Kay Thomson Tetrault. 2001. The Feminist Classroom: Dynamics of Gender, Race, and Privilege. Expanded ed. Lanham: Rowman \& Littlefield.

Mitchell, Sally. 1983. Dinah Mulock Craik. Boston: Twayne Publishers.

Mitchell, Charlotte, Ellen Jordan and Helen Schinske. n.d.. Letters of Charlotte Yonge. https:// c21ch.newcastle.edu.au/yonge/.

Oliphant, Margaret. 1887. “Mrs. Craik.” Macmillan's Magazine 57: 81-85. 
Rockwell, Geoffrey and Stéfan Sinclair. 2014. “Acculturation and the Digital Humanities Community.” In Digital Humanities Pedagogy: Practices, Principles, and Politics, 177-211. Cambridge: Open Book Publishers. http:// books.openedition.org/obp/1635?lang=en.

Shattock, Joanne. 2015. “Becoming a Professional Writer." In The Cambridge Companion to Victorian Women's Writing, edited by Linda Peterson, 29-42. Cambridge: Cambridge University Press.

Stone, Marjorie and Keith Lawson. 2012. “'One Hot Electric Breath': EBB's Technology Debate with Tennyson, Systemic Digital Lags in Nineteenth-Century Literary Scholarship, and the EBB Archive.” Victorian Review 38 (2): 101-125. doi: doi: 10.1353/vcr.2012.0001.

Wernimont, Jacqueline. 2013. “Whence Feminism? Assessing Feminist Interventions in Digital Literary Archives." Digital Humanities Quarterly 7 (1). http://www.digitalhumanities.org/dhq/ $\mathrm{vol} / 7 / 1 / 000156 / 000156 . h t m l$.

\section{NOTES}

1 See Cohee et al, Maher and Tetrault, and Crabtree, Sapp, and Licona.

2 The Complete Writings and Pictures of Dante Gabriel Rossetti: A Hypermedia Archive, accessed February 27, 2018, http://www.rossettiarchive.org/.

3 Letters of Charlotte Mary Yonge, accessed February 27, 2018, https://c21ch.newcastle.edu.au/ yonge/.

4 The Olive Schreiner Letters Online, accessed February 27, 2018, https://www.oliveschreiner.org/.

5 We are currently developing an ODD file, but worked without one for the first three years on this project as we developed our encoding standards. (We do check that @xml : ids, the place that coders are most prone to error, are correct using a schematron file, modeled on the one for Digital Mitford which Elisa Beshero-Bondar generously shared with us.) In part because we hire a small number of research assistants who have shown themselves to be meticulous in their term work, we find that our project members adhere for the most part to the tagset that we have defined in the Digital Dinah Craik codebook and do not need to be regulated by a prescriptive schema. We manually identify misused and unexpected tags when we check each other's encoding, and we discuss alterations and additions to our tagset as a group.

6 At the beginning of each new work term, we check in with our project members to ask if they have access to laptops or if we should book weekly time in one of the University of Calgary's computer labs. Thus far, we have been able to rely on our personal laptops, but we recognize that 
it is problematic to assume this will be the norm for our future collaborators. The University of Calgary Libraries and Cultural Resources has recently opened a collaborative digital workspace called LabNEXT, and in the future we plan to address this issue by booking desktop computers equipped with oXygen licenses.

7 Hansman's widely cited article takes the cognitive apprenticeship model of learning and its stages from Barbara LeGrand Brandt, James A. Farmer, Jr., and Annette Buckmaster's 1993 article, "Cognitive Apprenticeship Approach to Helping Adults Learn."

8 Our Digital Dinah Craik Codebook is available for download on our project GitHub at https:// github.com/kbourrier/Digitalcraik.

\section{AUTHORS}

\section{KAILEY FUKUSHIMA}

Kailey Fukushima is a master's student in English at the University of Victoria. She earned her bachelor's degree (honors) from the University of Calgary in 2016. Her research interests include Victorian popular literature and culture, food studies, cultural studies, and the digital humanities. Kailey was formerly the project manager of Digital Dinah Craik-a digital edition of Dinah Craik's correspondence-and has also worked in Special Collections and Digitization and Repository Services at the University of Calgary Libraries and Cultural Resources. She is currently a Research and Teaching Assistant in the University of Victoria's Department of English.

\section{KAREN BOURRIER}

Karen Bourrier is Associate Professor of English at the University of Calgary. Her research interests include Victorian literature and culture, disability studies, and the digital humanities. She is the author of Victorian Bestseller: The Life of Dinah Craik (U Michigan P, 2019) and The Measure of Manliness: Disability and Masculinity in Mid-Victorian Fiction (U Michigan P, 2015). She is project director of a digital resource peer-reviewed by NINES, Nineteenth-Century Disability: Cultures and Contexts, as well as PI for Digital Dinah Craik. 